Scientiæ Studia, São Paulo, v. 12, n. 2, p. 3०9-29, 2014

\title{
sit \\ Primatologia, culturas não humanas e novas alteridades
}

\author{
Eliane Sebeika Rapghan \\ Walter Alves Neves
}

\begin{abstract}
茴
RESUMO

De modo semelhante aos rompantes etnocêntricos de uma cultura humana frente a outras, as relações entre humanos e primatas não humanos incluem um estranhamento pontuado por atração e repulsa, identificação e diferença. Ciência, arte e mitologia são a expressão viva e atualizada disso. Desde 1960, a primatologia destaca-se nesse cenário por contribuir significativamente na revisão das definições sobre o comportamento dos primatas e, consequentemente, na redefinição do humano ao apresentar a polêmica proposição de existência de "culturas" entre animais não humanos. Assim, a aproximação entre humanos e primatas não humanos parece inexorável e irreversível. Isso implica, por exemplo, em cogitar se esse processo engendra, ou não, a constituição de novas alteridades a partir de um novo outro (não humano), carregado de significados. Isso incluiria, por exemplo, a reformulação de representações e de categorias de classificação, bem como o aprofundamento do debate sobre os direitos dos animais não humanos. Ao dirigir tal tipo de desafio a situações de pesquisa antropológica deve-se ter aguda consciência de que o registro etnográfico das relações entre humanos e os outros primatas será uma construção empírica, perceptual e teórica. Dado o tipo particular de relação estabelecida entre humanos e outros primatas, pautada em um universo fronteiriço de incômodas semelhanças e diferenças, constituem-se aí coletivos híbridos em que o alcance e a profundidade das interações possíveis ainda são desconhecidos.
\end{abstract}

Palavras-chave • Alteridade. Animalidade. Coletivos híbridos. Culturas de chimpanzés. Etnografia. Híbridos. Humanidade. Relações entre humanos e não humanos.

\section{Sobre AS GoncePções DE ANIMAL, DE humano,} DE ANIMALIDADE E DE HUMANIDADE

O antropólogo Tim Ingold (1994) problematiza e analisa, de um lado, as definições de "humano" e de "animal", e, de outro, as definições de "humanidade" e de "animalidade" a partir do pressuposto de que ambas, apesar das semelhanças entre os termos e das analogias entre as relações, correspondem a exercícios intelectuais essencialmente distintos. O primeiro exercício implica, por exemplo, no enfrentamento de problemas conceituais referentes à universalidade das espécies, à unidade biológica e ao fato de estarmos, como seres vivos, submetidos à evolução. No caso dos humanos, refere- 
se também a definições de caráter evolutivo (ou histórico, como prefere Ingold) que contemplam as capacidades universais humanas para produzir cultura, linguagem ou pensamento complexo. Ou seja, definir "humano" ou "animal" implica em contribuir com a constituição de uma categoria universal. É o exercício de produzir conceitos no sentido científico que demanda a ênfase nas regularidades e nas semelhanças entre indivíduos ou coletividades.

O segundo exercício, relativo à produção de concepções de "humanidade" e de "animalidade", por sua vez, está associado ao processo de reconhecimento de si e dos outros como membros desses conjuntos. A definição de humanidade implica na identificação de si e dos outros como humanos ou mesmo como membros de determinada cultura ou sociedade humana. Os processos de produção de conhecimento voltados a refletir sobre, por exemplo, o que caracteriza a humanidade ou a animalidade, tanto em âmbito universal quanto específico, correspondem a práticas intelectuais que manejam, necessariamente, ordens simbólicas, como é o caso da concepção maussiana de "pessoa" (cf. Mauss, 2003) que projeta ideias de pertencimento, consciência de si e formas de ser no mundo.

Assim, a tradição do pensamento moderno ocidental dual, que frequentemente hierarquiza as categorias de classificação que produz (cf. Corbey \&Theunissen, 1995; Latour, 1994; Santos, 1988) e que insiste em definir o humano a partir de qualidades supostamente ausentes nos animais, depara-se com o paradoxo segundo o qual os humanos são animais, mas sendo humanos, representam o que está ausente na caracterização de um animal (cf. Ingold, 1994). O humano é definido pela negação ou superação do que se entende por animal. Daí o grande desafio inerente à proposição de redefinição do que é humano e do que é animal que se coloca cada vez mais insinuantemente desde, pelo menos, a década de 1990.

Nas últimas décadas o enfoque das biociências expandiu-se da anatomia e da fisiologia dos seres para abordagens e objetos que tratam, da perspectiva evolutiva, de comportamentos sociais e de capacidades cognitivas. Trata-se, portanto, de lidar com a herança tanto de caracteres físicos quanto cognitivos e sociais e, por isso mesmo, reconhecer e analisar o papel das interações grupais no pleno desenvolvimento desses caracteres. Neste domínio, a teoria do instinto que serviu durante décadas para explicar o comportamento dos animais não humanos por contraste negativo com o comportamento humano torna-se cada vez mais insatisfatória, ao menos para as chamadas espécies sociais e, dentre estas, para aquelas que têm maior proximidade evolutiva com os humanos, os monos (bonobos, chimpanzés, gorilas e orangotangos). Abordagens teóricas como a coevolução gene-cultura (cf. Richerson \& Boyd, 2005), o modelo de "cérebro social" (cf. Dunbar, 2002; Dunbar \& Schultz, 2007), a socioecologia evolutiva (cf. Alvard, 2003; Betzig, 1997; Smith, 2000; Irons \& Cronk, 2000; Witerhalder \& Smith, 
1992) e a sociobiologia (cf. De Waal, 2004; Galdikas \& Vasey, 1991; Gilmore, 1981) surgiram com o propósito de tratar, da perspectiva evolutiva, fenômenos não físicos.

Isso coloca para as ciências sociais e humanas novas questões frente às biociências. Por exemplo, como justificar uma definição de humano pautada na exclusividade da capacidade de produzir cultura, linguagem e raciocínios complexos, quando se verifica que não humanos em estado selvagem, como os chimpanzés (cf. Boesch, 2003, 2011; De Waal, 2005b; Whiten \& Boesch, 2001; Whiten, 2010; Whiten et al. 1999; Wrangham et al. 2001) ou os cetáceos (cf. Rendell \& Whitehead, 2001), produzem e reproduzem, através de gerações, comportamentos padronizados, aprendidos no interior de seus grupos sociais, relacionados ao uso de ferramentas (cf. Boesch \& Boesch, 1990; Davidson \& McGrew, 2005; McGrew, 1992), à comunicação corporal e vocal (cf. Arcadi, 2000, 2005; Arnold \& Zuberbühler, 2008; Boesch, 1991; Burling, 1993, 2007; King, 2004; Kojima, Izumi, \& Ceugniet, 2003; Lachmann, Számadó \& Bergstrom, 2001; Pika \& Mitani, 2006) e às interações sociais (cf. Arcadi \& Wrangham, 1999; Arnold \& Withen, 2001; Lycett, Collard \& McGrew, 2010; Stanford, 1998; McGrew \& Tutin, 1978; Zeller, 2001; Whiten, 2010)? Diante disso não se pode mais caracterizar o humano como o único ser exclusivamente social ou capaz de resolver problemas, nem se pode mais afirmar que a cultura é uma segunda natureza para os humanos, capaz de substituir integralmente as características de sua condição física de animal sem apresentar contra-argumentos satisfatórios em relação às capacidades e comportamentos verificados em outras espécies.

No plano da produção das definições de "animalidade" e de "humanidade", a antropologia sociocultural desempenhou um papel importante ao longo de todo o século xx. Os registros etnográficos produzidos sobre populações humanas distribuídas por todo o planeta ofereceram subsídios para incluir todos os membros de qualquer cultura humana na categoria que contempla o que se entende por "humanidade", segundo as concepções ocidentais, como pessoas morais, semelhantes, apesar da diversidade. Ou seja, os "outros" humanos passaram, por meio da antropologia, a constituir uma alteridade e uma pluralidade contida pelo que se entende por humanidade. São humanos porque somos da mesma espécie, porque somos todos capazes de produzir, em sociedade, linguagem e ordens simbólicas complexas que remetem a formas de existência reconhecidas como expressões de humanidade. Esses "outros" fazem parte da humanidade porque possuem e produzem conhecimento técnico, relações de parentesco, intersubjetividade, sistemas de trocas e rituais, concepções estéticas, morais e de poder. Eles se reconhecem como expressões da humanidade, mesmo que seja exclusivamente no âmbito de suas próprias culturas, e são reconhecidos como membros da humanidade a partir de uma perspectiva ocidental e universalista. Foi preciso que os antropólogos, por meio do recurso metodológico pautado no relativismo cultu- 
ral, demonstrassem que o que o etnocentrismo ocidental classificava como "exótico", "estranho", "repugnante" ou "moralmente condenável” não é "animalesco". São, sim, práticas contextualmente legítimas e justificáveis em culturas e sociedades específicas. São expressões diversas da "humanidade". Para fazer isso, a maior parte das correntes antropológicas supervalorizou a diversidade das culturas humanas em detrimento da unidade da espécie. Uma das consequências disso foi a produção de distâncias conceituais imensas entre os parâmetros aceitáveis da humanidade, constituída por seres essencialmente socioculturais, e a animalidade. Ao fazer isso, muitas correntes antropológicas submeteram, em teoria, nossa condição animal ao domínio da cultura, diluíram nosso estatuto de espécie e apartaram-nos de nossa existência natural enquanto seres vivos.

De fato, fazer parte da humanidade não implica apenas em ser humano, mas também em ser reconhecido como par em termos de direitos e de complexidade, significa compor relações nas quais identidades e alteridades revezam-se em uma dinâmica de autorreconhecimento mútuo. Obviamente, trata-se de uma rede desigual, conflituosa e dinâmica de relações em que diferenças sociais, culturais, étnicas e de gênero, entre outras, confrontam ou reforçam valores morais e relações desequilibradas de poder. A animalidade, por sua vez, é tradicionalmente atribuída àqueles que não são reconhecidos no âmbito da humanidade. Repete-se aqui a classificação baseada em um princípio dual e hierárquico. Nesse plano, a animalidade é classificada a partir da ausência dos atributos em que os humanos se reconhecem. Ela é uma categoria que indica pertencimento, como aliás a de "humanidade", com a diferença de que pertencer à animalidade tem um caráter passivo, pois é uma condição atribuída. Pertencer à humanidade tem caráter ativo, pois implica em reconhecer como humano a si e a outros. Ou seja, os representantes da humanidade podem atribuir, recusar, aceitar, reivindicar ou manipular seu pertencimento a essa categoria. Eles são sujeitos porque são humanos. Os representantes da animalidade, submetidos à classificação, não reagem nos mesmos termos.

Por décadas, desde a constituição de um discurso antropológico não etnocêntrico, o pertencimento à humanidade foi identificado entre os seres reconhecidamente capazes de produzir cultura e linguagem, dotados de inteligência e forjados para viver em sociedade. Os violentos encontros entre europeus e não europeus desde a chegada dos primeiros à América, por sua vez, constituíram-se por parâmetros de classificação, de modo que a busca de sinais como a existência da alma (cf. Hanke, 1994), da fé, da lei e do rei (cf. Clastres, 2012) foram precursoras de mecanismos hierárquicos de classificação dos critérios de pertencimento à humanidade. Em que pesem as enormes diferenças, em ambos os casos, ter ou não ter certos atributos identificáveis por especialistas foi a pedra de toque desses exercícios de classificação. 
Desse modo, a partir das perspectivas apresentadas, as reflexões que se seguem sobre as assim chamadas "culturas de chimpanzés", sobre a possibilidade de constituição de alteridades não humanas e sobre o potencial de alargamento das categorias "humano" e "humanidade" serão orientadas por esses parâmetros.

\section{ReLações ENTRE ANTropologia e PRIMATOlogia PELA VIA DA GULTURA}

Desde a década de 1960, os resultados de pesquisas sobre o comportamento de chimpanzés selvagens acumulam-se e reforçam a existência e a importância de suas capacidades sociais, comunicativas, técnicas e naturalísticas, modificando profundamente as concepções correntes do que seja um animal e, consequentemente, do que seja um humano. No entanto, aparentemente, tal fato estrondoso não tem causado, nas ciências humanas e sociais, o alarde esperado, com algumas exceções (cf. Asquith, 2011; Ingold, 1994; Latour, 2000; Haraway, 1989, 1990; Lestel, 2002, 2004; Sperber, 1985; Rapchan \& Neves, 2005, no prelo; Waizbort, 2001). Tal passividade pode estar relacionada a causas distintas, tais como a biofobia ou o hiper-relativismo.

A biofobia pode levar a ignorar, reduzir e desvalorizar o impacto das biociências sobre as humanidades, de tal modo que o anúncio de descobertas nessas áreas não seja considerado algo que afete efetivamente nosso modo de pensar ou produzir conhecimento. No máximo, pode promover a elaboração de novos objetos de pesquisa sem que métodos, categorias de classificação, conceitos ou epistemologias relacionadas à produção de conhecimento na antropologia devam ser necessariamente repensados. Alguns antropólogos têm trazido contribuições relevantes ao tratar a abordagem sobre as culturas de chimpanzés como mais uma das definições possíveis de cultura, entre tantas outras. Por essa perspectiva, as culturas de animais são tratadas pelos antropólogos como fenômenos que emergem aos olhos dos primatólogos como expressões localistas e holísticas, tal como ocorre com a abordagem antropológica das culturas humanas e, portanto, também submetidas às projeções simbólicas dos biocientistas, sem que os mesmos se deem conta disso (cf. Asquith, 2011; Sá, 2013).

Entretanto, em tais contextos de abordagem, é preciso ficar alerta em relação ao hiper-relativismo e não esquecer dos contextos acadêmico e social do debate. Ou seja, os primatólogos produzem um conhecimento cuja legitimidade está atrelada ao poder do discurso científico e cujo impacto sobre a sociedade não pode ser minimizado. Além disso, em uma perspectiva distinta, o conhecimento acumulado sobre os monos nas últimas cinco décadas afeta intensa e intimamente o estatuto do humano tal como constituído desde o Iluminismo (cf. Rapchan, 2012) e será necessário apresentar bons 
argumentos para justificar que eles não podem ser integrados às categorias da humanidade, como se verá adiante.

Ao mesmo tempo, é provável que a reclassificação de humanos e de animais a partir de critérios distintos dos estabelecidos no Ocidente nos últimos séculos (cf. Asquith, 1995) não redefina apenas nossos objetos de pesquisa, mas interfira também em nossos parâmetros epistemológicos e em nossas teorias, assim como nas leis, parâmetros éticos, valores e condutas sociais. Contudo, não é possível afirmar se isso modificará aquilo que entendemos por humanidade. Nos termos de Latour (1994), a constituição da ciência moderna garante que os objetos das ciências naturais sejam purificados e os das ciências sociais operem por mediação, de modo que natureza e sociedade permanecem absolutamente distintas no processo de produção do conhecimento. Assim, o que observamos diante de alguns objetos de pesquisa, tais como as "culturas de chimpanzé", é a emergência de híbridos entre natureza e sociedade (cf. Latour, 1994, 2000), que são resilientes à compreensão a partir de áreas de conhecimento restritas. Sendo assim, em que pese a grande probabilidade de nossas concepções de humanidade não se alterarem significativamente diante da ideia de "culturas de chimpanzés", é provável, contudo, que as relações entre humanos e não humanos sejam incluídas no rol contemplado pelas concepções de humanidade e tornem-se crescentemente objeto de análise (cf. Ingold, 1994; Rapchan \& Neves, no prelo).

Essa atitude reativa, muito afeita às definições correntes do humano, é expressa na recusa da antropologia ao diálogo com as biociências com base na premissa de que a cultura, no sentido antropológico, é um fenômeno essencialmente humano e, por isso, não humanos não possuiriam cultura. Nessa perspectiva tautológica, sendo a cultura um fenômeno essencialmente humano, é impossível atribuir cultura a qualquer outro ser vivo que não seja classificável como humano. No entanto, mesmo que cheguemos à conclusão de que a definição de cultura em seu sentido antropológico só é aplicável à humanidade, isso não quer dizer que as noções de "culturas de chimpanzés" e mesmo de "culturas de animais" não devam ser analisadas por perspectivas distintas da antropologia, a fim de obter um conhecimento que possa ser revertido em reflexões sobre as concepções de humano e animal, bem como de humanidade e de animalidade.

\section{Sobre AS Gongepções DE GUltura NA ANTropologia E NA PRIMATOlOGia}

Desde o anúncio feito na revista Nature (cf. Whiten et al., 1999) por um grupo de eminentes primatólogos que chimpanzés selvagens possuem cultura, há muito o que pensar diante da definição do que é humano e do que é animal. De fato, desde meados de 1960, um crescente número de trabalhos sobre o comportamento de chimpanzés sel- 
vagens oferece registros consistentes que enfocam a importância da interação social e da cognição na plena realização e expressão de sua ontologia como seres. Um dos aspectos surpreendentes desses dados é que eles se referem a fenômenos que não são inatos, mas são repassados por relações intergeracionais de aprendizado social, obedecendo a padrões que variam entre os grupos e que são, simultaneamente, muito homogêneos no interior de um mesmo grupo e passíveis de inovação e de variar em relação ao meio (cf. Hrdy, 2000; Wrangham et al., 2001; Fedigan, 1992; Tomasello, 1994; Goodall, 1965, 1991). Esse material surpreende e questiona de modo arrebatador as concepções ocidentais até há pouco vigentes de humano e de animal.

Jane Goodall (1965), pioneira nesses estudos, por exemplo, distinguiu em Gombe (Tanzânia) padrões de comportamento diário (cf. Goodall, 1965, p. 429-3o) e os efeitos da sazonalidade sobre o comportamento de chimpanzés (cf. p. 434-5). Registrou também variantes nos comportamentos individuais, grupais e nas interações intergrupais. O registro do comportamento individual contemplou locomoção, comportamento sexual, alimentação, grooming e a construção de ninhos. Em termos de comportamento grupal, a autora distinguiu relações de dominância, liderança e tolerância e, no plano das interações intergrupais, abordou comunicação, territorialidade e conflito. Goodall também escreveu sobre o desenvolvimento físico e social dos filhotes, as interações sociais dos chimpanzés juvenis e as expressões corporais, faciais e vocais que remetem ao relaxamento, ataque, submissão, alarme, rejeição ou incerteza.

Nas décadas seguintes, além de continuar a explorar esses conjuntos de fenômenos, as pesquisas passaram também a registrar e a promover comparações intergrupais baseadas em repertórios de ferramentas (cf. McGrew, 1992), na dieta (cf. Watts et al., 2012), na dinâmica e centralidade das relações mãe-filhote (cf. Hrdy, 2000) e na avaliação de capacidades cognitivas (cf. Tomasello \& Call, 1997; Matsuzawa, 2001; McGrew, 2001; Nishida, 1987). Em laboratório, há estudos sobre sinalização com fins de comunicação, autorreconhecimento, percepção espacial, representação, aprendizado, invenção e desenvolvimento de habilidades classificatórias e numéricas (cf. Parker \& Gibson, 1994). A partir de análises comparativas, pesquisadores têm afirmado encontrar, entre os chimpanzés, expressões que têm denominado "chimpanzeecultures" (cf. Wrangham et al., 2001), "primate social conflict" (cf. Mason \& Mendoza, 1993) ou "chimpanzeepolitics" (cf. De Waal, 2000).

Contudo, cabe também ressaltar que, à medida que a socialização e a sociabilidade foram sendo mais bem compreendidas, as semelhanças e diferenças verificadas e reconhecidas entre chimpanzés selvagens e chimpanzés de laboratório também se acentuaram. Isso reforçou a percepção de como o potencial para o aprendizado e para a vida em grupo, característicos da espécie, varia de acordo com os contextos e mesmo em termos do comportamento individual (cf. Goodall, 1965; De Waal, 2005a). 
De uma perspectiva ontológica, chimpanzés selvagens e chimpanzés de laboratório são seres distintos.

Nesse sentido, é uma assertiva profunda e impactante a afirmação de que cada grupo de chimpanzés em estado selvagem é o produto e a expressão de certa cultura a qual se expressa através de um conjunto extenso e definido de comportamentos estáveis, reproduzidos por gerações, socialmente aprendidos e que variam de grupo para grupo. Aliás, os primatólogos afirmam a existência de "culturas de chimpanzés", no plural, porque cada grupo possui um arranjo único de padrões de comportamento, o que caracterizaria indelevelmente um grupo e seus membros. Na mesma direção, segundo alguns pesquisadores (cf. Carpenter, Tomasello \& Savage-Rumbaugh, 1995), chimpanzés que crescem e vivem em laboratório têm sido denominados como seres "aculturados" pelo convívio humano. Ou seja, entre os chimpanzés de laboratório, o potencial cognitivo e a centralidade da vida em grupo manifestam-se nas condições disponíveis, que dependem, seja dos grupos de pesquisadores humanos, seja de comunidades híbridas formadas por humanos e chimpanzés.

Por outro lado, as concepções antropológicas de cultura humana são, como quase todos sabem, imprecisas (cf. Ellen, Lycett \& Johns, 2013; Akhil \& Ferguson, 1997; Ingold, 1996, 2001; Geertz, 1978; Kuper, 1999). Entretanto, desde a segunda metade do século $\mathrm{xx}$, quase todos os antropólogos concordam que é possível remeter todas as culturas humanas aos fenômenos associados a significados e sentidos coletivos, ou seja, à intersubjetividade. O humano é, enfim, um ser simbólico. Assim, como antropólogos que somos, a expressão "culturas de chimpanzés" aguçou intensamente a curiosidade dos autores. Perguntamo-nos: teriam os primatólogos encontrado uma definição geral de cultura? Se sim, ela dialoga com a antropologia? Sob quais perspectivas? Eles consideraram o aspecto simbólico essencial à definição antropológica de cultura? Será que os primatólogos resolveram o problema relativo ao paradoxo da pluralidade cultural frente à universalidade da espécie? Eles mantiveram ou superaram dualidades intrínsecas a concepções como local versus universal ou natureza versus cultura?

Decidimos, então, analisar os artigos que apresentavam as "culturas de chimpanzés" como ideia central, publicados em 26 periódicos internacionais representativos da área no período de 1999 a 2011, plurais em sua ênfase e de alto impacto na comunidade científica. Esse período foi definido em função do reconhecido impacto que o artigo sobre as culturas de chimpanzés (Whiten et al., 1999) causou sobre a primatologia ocidental (cf. Perry, 2006). Um exame sistemático das definições correntes de "culturas de chimpanzés" foi feito com o intuito de identificar e analisar as concepções de cultura utilizadas pelos primatólogos. Encontramos um total de 102 artigos, nos quais a abordagem das culturas de chimpanzés é um elemento central. Observando esse conjunto, separamos inicialmente os que apresentavam alguma definição de cultura, che- 
gando a $84(82,4 \%)$, dos que não apresentavam qualquer definição, ou seja, 18 artigos $(17,6 \%)$. Contudo, verificamos que dentre os 84 artigos selecionados, 4 o deles $(39,2 \%)$ oferecem uma definição explícita de cultura, enquanto outros $44,(4,3,1 \%)$ apresentam apenas sugestões ou definições implícitas de culturas de chimpanzés. Assim, se reunirmos os artigos que não apresentam definição alguma aos que só apresentam definições implícitas, teremos um conjunto significativo formado por 62 artigos (6o,8\%). Esse conjunto é constituído por um grupo de artigos que não apresenta uma definição clara nem consistente para o termo "cultura".

Tais resultados sugerem dois caminhos para reflexão. Em um deles, a causa maior para a não apresentação de definições repousaria na hipótese de que há um consenso em torno de uma noção de cultura, o que justificaria a ausência da necessidade de apresentar uma definição ou de aderir a fontes bibliográficas já conhecidas entre os especialistas. Nesse caso, podem ser supostas duas alternativas para desvendar o mistério: ou os primatólogos consideram desnecessário definir cultura, dado que é um fenômeno íntima e empiricamente conhecido por todos os humanos e, portanto, a vivência ofereceria os elementos necessários para a definição, ou eles já chegaram a um consenso em relação ao que seja cultura, de modo que se torna desnecessário reproduzir a definição a cada vez que ela é mencionada. Nesta última alternativa, provavelmente encontraríamos constantes referências a uma definição que estaria na origem do uso do termo "cultura" pelos primatólogos, mas isso não ocorre. No outro caminho, em contrapartida, pode-se considerar que a ausência de definições aponta para a incerteza, sugerindo a dificuldade de apresentação dos elementos que dão suporte a uma concepção de cultura aplicável ao comportamento dos chimpanzés selvagens, apesar do uso do termo parecer adequado aos pesquisadores. As causas precisas para essa ausência ou falta de explicitação ainda não estão completamente claras para nós e demandam análises futuras sobre o material colhido. De qualquer modo, esses resultados indicam que é importante refletir por que uma abordagem tão impactante, como a que sugere que não humanos possuem cultura, seja tão pouco clara na apresentação, por parte dos pesquisadores, do que eles entendem por esse termo.

No geral, pode-se afirmar que todos os artigos que oferecem uma definição implícita para "culturas de chimpanzés" associam, predominantemente, a cultura à variabilidade de comportamentos, fenômeno que costuma estar associado à transmissão ou ao aprendizado social, frequentemente avaliados em relação às influências genéticas ou ecológicas sobre sua expressão. Essas ideias não são completamente originais para os chimpanzés porque também fundamentam concepções gerais sobre "culturas animais" e sinalizam a partilha de um núcleo conceitual evolutivo comum referenciado nas ideias darwinianas. Nos 4,0 artigos que oferecem uma definição explícita para o termo "culturas de chimpanzés", a ênfase recai sobre as várias formas de transmissão 
dos padrões de comportamento: aprendizado, transmissão, dinâmica social e comunicação. Isso pode estar relacionado a um esforço em explicar o grande número e a significativa variabilidade de comportamentos já registrados. A análise do conjunto sugere que a iniciativa visa atender dois tipos de demanda: o debate com os críticos de outras áreas, da etologia (cf. Galef, 1992) à antropologia (cf. Ingold, 1996, 2001; Rapchan \& Neves, 2005), ou a iniciativa em favor do refinamento do instrumental teórico.

Considerando nossa crítica que questiona a validade do uso do termo "cultura" para definir e explicar o comportamento de chimpanzés selvagens, é importante destacar que, desde sua origem, a proposição dessa pesquisa nunca se baseou em "biofobia" nem em uma defesa intransigente e metafísica da singularidade humana. Ao contrário das primeiras investidas da antropologia para explicar a diversidade cultural humana, não apostamos na hipótese da "tábula rasa". Reconhecemos que humanos são seres vivos e, portanto, submetidos constantemente a processos evolutivos, inclusive em suas capacidades linguístico-cognitivas (cf. Pinker, 2013) e de produzir cultura (cf. Klein, 2009[1999]). Não temos hostilidade prévia à ideia de "culturas de animais", mas defendemos que ela merece uma análise crítica e pluridisciplinar. Ou seja, não recusamos a possibilidade de existência de culturas em outras espécies, desde que se comprove seu caráter simbólico, que é a essência da concepção antropológica de cultura, construída ao longo de mais de 150 anos da história da disciplina e que consideramos absolutamente legítima.

Na primatologia, McGrew e Tutin (1978) foram, provavelmente, os primeiros pesquisadores ocidentais a aplicar a ideia de "cultura" a dados sobre variações intergrupais para o grooming entre chimpanzés selvagens pertencentes a populações distintas. Para isso, eles se basearam nas concepções de cultura dos antropólogos Edward Tylor (1832-1917), Alfred Kroeber (1876-1960) e Clyde Kluckhohn (1905-1960) (cf. Lestel, 1998, p. 211; Davidson \& McGrew, 2005, p. 796; Perry, 2006). De Kroeber e Kluckhohn adotaram os seis critérios propostos para identificar cultura: inovação, disseminação, estandardização, durabilidade, difusão, tradição. A esses fatores, McGrew e Tutin acrescentaram a não subsistência (nonsubsistence), isto é, comportamentos não associados à sobrevivência, e a naturalidade, ou seja, comportamentos não estimulados por influência humana (cf. Lestel, 1998, p. 211). Curiosamente, o aspecto que aproxima a síntese da concepção de cultura proposta por Kroeber e Kluckhohn (cf. 1952, p.153) da capacidade de simbolização, de generalização e de substituição imaginativa é muito raramente explorada pelos primatólogos e, quando ocorre, quase nunca se baseia em uma efetiva relação de troca intelectual. Segundo Lestel (cf. 1998, p. 211), embora nenhuma população de chimpanzés apresente todas essas características simultaneamente, a cada critério indicado correspondem dados sobre o comportamento que são dignos de nota. Atualmente, o núcleo dessa concepção persiste e influencia 
a maioria dos primatólogos dedicados a encontrar comportamentos culturais entre os chimpanzés, apesar de ser raramente explicitada. O impacto tardio do artigo publicado por McGrew e Tutin assinala que a maioria dos primatólogos ocidentais, indiferentes à "questão da cultura" até a década de 1990, com raras exceções, abraçou fortemente, a partir de então, o propósito de investigar as "culturas de chimpanzés" (Perry, 2006, p. 172).

Em nossa pesquisa, percebemos que, apesar de os primatólogos buscarem uma definição universal e sintética de cultura, o que eles apresentam é vago, genérico e pouco discutido, mesmo quando oferecem uma definição explícita do termo. Ou seja, nossa conclusão é que se os antropólogos sociais não elaboraram um conceito claro para cultura, tampouco os primatólogos atingiram esse intento. Mas que problema há nisso? Como Ingold (2001) já mencionou, as concepções de cultura escolhidas pelos primatólogos estão ultrapassadas. A maioria dos antropólogos submeteu essas concepções a críticas, reconheceu sua extrema limitação, abandonando-as há muito tempo. Os antropólogos descartaram-nas, não apenas devido a um problema conceitual, o que, por si, já seria o bastante, mas porque essa concepção de cultura não oferece explicações satisfatórias para o fenômeno cultural humano tal como concebido pela antropologia e registrado pela etnografia.

No que diz respeito à definição de humano e de animal, usar o termo "cultura" para qualificar a segunda, apesar de impactante, não contribui significativamente, porque é vago. Há apenas uma coincidência de nomes, já que o fenômeno chamado cultura pelos primatólogos não corresponde ao que os antropólogos chamam hoje de cultura. Ou seja, o questionamento das fronteiras da definição não acontece e os animais, apesar de receberem novos atributos, continuam sendo expressões de incompletude ou ausência diante da definição de humano. O que realmente impacta na definição de humano e de animal são os resultados das pesquisas sobre o comportamento e a cognição de chimpanzés selvagens e em laboratório.

\section{RedefiniçÃ̃o de ANIMAL, REDEFINIÇÃo DE HUMANO}

Para que a redefinição de animal e de humano supere a dicotomia fundada na presença ou na ausência de características, será preciso reorientar os fundamentos dessas categorias e, por exemplo, pensar sobre o quanto são rígidos, porosos ou fixos os marcos que definem e distinguem os humanos dos outros animais (cf. Lestel, 2004). Abordagens que explorem o que os chimpanzés são em si, enfocando sua complexidade individual e grupal nas relações com o meio (cf. Ingold, 2001, p. 3oๆ), também contribuirão para isso. Há primatólogos que rejeitam as concepções antropológicas de cultura 
por considerá-las demasiado antropocêntricas (cf. De Waal, 1999, p. 635; Whiten, Schick \& Toth, p. 2009, p. 424) e propõem definições mais gerais, válidas para as outras espécies. Eles supõem, ingenuamente, que, por essa via, a perspectiva evolutiva será reforçada. Contudo, definições mais gerais de cultura, como é o caso das "culturas de chimpanzés”, não anulam a importância dos fenômenos que não conseguem abarcar. Assim, a cultura como fenômeno essencialmente simbólico e as abordagens teóricas da antropologia continuam a fazer referência à definição de humano. A definição de animal, por sua vez, transforma-se muito mais pelo impacto dos estudos que revelam a complexidade comportamental do que pela associação com a palavra cultura.

Em contrapartida, de um ponto de vista evolucionista, a tomada de conhecimento sobre as complexidades comportamentais e cognitivas dos chimpanzés e de outros animais não humanos propõe reflexões que incluem a condição de animal, de ser vivo, na definição de humano. Por essa perspectiva, elas convergem em direção a outras abordagens surgidas recentemente na antropologia biológica, na paleoantropologia e na psicologia evolutiva. Apesar de muito distintas, todas essas abordagens estão envolvidas com esforços em recuperar a natureza na compreensão da condição humana. Ao definir o humano como ser cultural e como ser vivo e, portanto, submetido a pressões evolutivas, surgem novas questões. Por exemplo, as modificações herdadas que conduziram ao surgimento do humano moderno há cerca de 50 mil anos ocorreram apenas nos genes (Smith, 2000)? Ocorreram só no funcionamento do cérebro ou dependeram também de fatores sociais, comportamentais e ambientais (cf. Drennan, 1991; Henrich \& McElreath, 2003; Mithen, 2002, 2007; Tooby \& Cosmides, 1992; Weiss \& Hayashida, 2002)? Estão associadas a um processo evolutivo paralelo dos genes e da vida social (cf. Moran, 1991)? Estão associadas a uma coevolução gene-cultura (cf. Richerson \& Boyd, 2005)?

O aparecimento do humano como ser cultural, em termos evolutivos, foi um processo gradual ou um "salto"? Se gradual, é provável que se encontrem manifestações culturais análogas em hominídeos fósseis como os Neandertais (cf. Arsuaga, 2007) e mesmo em outras espécies, monos, cetáceos e aves, como os corvos da Nova Caledônia (cf. Holzhaider et al., 2011; Laland, 2008; Laland \& Galef, 2009; Poirier \& Fitton, 2001; Whiten, 2005a, 2005b). Se houve um "salto evolutivo" (cf. Gould, 1977, 2002; Rapchan \& Neves, 2005), uma "revolução humana", então a cultura humana é única (cf. Diamond, 2013; Janson \& Smith, 2003, p. 57-8; Klein, 2009; Mithen, 2002, 2007). E esta afirmação, vale enfatizar, não é redutoramente antropocêntrica, ao contrário do que defendem alguns primatólogos (cf. Boesch, 2003; De Waal, 1999; McGrew, 2004; Whiten, 2005a, 2005b). Há inúmeras características que são únicas para uma dada espécie (cf. Foley, ${ }_{1987}$ ). O canto das baleias (cf. Rendell \& Whitehead, 2001) é um ótimo (e não exclusivo) exemplo disso. 


\section{Humanidade E ANIMALIDADE: NOVAS ALTERIDADES?}

O que é a alteridade senão a definição de um outro reconhecido, um outro que deixa de ser o que era porque, de algum modo, passou a ser incluído em um sistema de classificação e de pensamento que abrange a nós mesmos e, através disso, passou a coexistir e a compartilhar conosco algo que entendemos ser parte constituinte, ainda que parcialmente, de nossa própria identificação com o outro? Nesse sentido, estaria a primatologia, tal como a antropologia nos séculos XIX e Xx, percorrendo uma jornada intelectual em favor da construção de um novo outro, de um outro não humano, a fim de integrá-lo à humanidade? O primatólogo Craig Stanford (2001) sugere que as mudanças recentes ocorridas na primatologia e as modificações que alteraram as relações que estabelecemos com os primatas não humanos, bem como as representações que fazemos deles, sugerem a constituição de uma nova alteridade elaborada a partir da constituição de um outro (não humano). A seguir serão analisados alguns desses mecanismos.

A expressão "culturas de chimpanzés", como se pretendeu demonstrar, apesar de equivocada do ponto de vista antropológico, está atrelada a descobertas sobre o comportamento e a cognição que certamente terão forte impacto sobre as definições de humano e de animal. Contudo, a constituição de alteridades não humanas diz respeito à reconfiguração das definições de humanidade e aí temos outros problemas. Os chimpanzés são os primeiros da lista de espécies não humanas sobre as quais se tem criado representações carregadas de significados favoráveis à constituição de semelhanças com os humanos, entre elas, a atribuição da capacidade para produzir - o que os primatólogos chamam cultura - o reconhecimento da condição de pessoa (cf. Lestel, 2004; Cavalieri \& Singer, 1995), a definição de questões de ética relacionadas a não humanos (cf. Armstrong \& Bitzler, 2003) e a defesa de direitos mais amplos do que apenas a sobrevivência de indivíduos ou da espécie. Mas a proposição de que um animal seja uma pessoa com direitos significa a mesma coisa que a pessoa moral que inclui um humano no âmbito da humanidade? Atribuir cultura a um animal, considerando que o que se chama de cultura não é o fenômeno "cultura" no sentido humano, é construir uma alteridade não humana? Arriscamo-nos a afirmar que não, mas nossos argumentos precisam ser apresentados em dois níveis distintos: o do direito geral e o de relações locais e específicas.

Há intelectuais e juristas discutindo o assunto no âmbito da ética e das constituições nacionais. O fundamento geral dos que defendem os direitos animais é que eles vivam como pessoas e não como propriedades. Leis nacionais na Nova Zelândia, América do Norte, Europa e Oriente Médio baniram ações cruéis contra animais. Em 2008, o parlamento espanhol votou resolução a favor de estender alguns direitos a primatas não humanos. Nesses casos, a extensão de direitos a um animal não humano 
e sua classificação como pessoa sugere direitos semelhantes e complexidades desiguais. $\mathrm{O}$ animal continua sendo considerado um ser de complexidade inferior. Além disso, ele recebe seus direitos dos humanos. Muda a concepção de animal, mas eles continuam sendo animais. No âmbito do direito, os animais são pacientes do processo. Eles dependem da ação humana orientada por determinações jurídicas para serem, por exemplo, protegidos. Não se trata de concordar aqui com os críticos aos direitos dos animais, que defendem que os animais não têm direitos porque não têm obrigações, não participando, assim, do contrato social. Mas, em que pese a importância positiva do direito do animal, trata-se também de avaliar os valores envolvidos nessas ações e pensar sobre seu alcance.

Sob outra perspectiva, Lestel, inspirado por Deleuze e Guattari (1980), enfoca o caráter de certas relações intensas estabelecidas entre os humanos e as outras espécies animais (cf. 2004, p. 14) em associações em que se partilham não somente interesses, mas também emoções e convívio. Ele as chama "comunidades híbridas", formadas por humanos e animais. Nesse nível, as relações humano/animal sugerem concepções como "indivíduos animais" e "pessoas animais" (Lestel, 2004, p. 14). Para analisar casos como esses, é necessário substituir os modelos "animal-objeto" ou "animal-máquina" cartesiano (cf. Lestel, 2004) por modelos em que animais não humanos sejam reconhecidos como sujeitos de ação nas relações. As categorias de pensamento que concebem animais não humanos como agentes colocam, por sua vez, novos problemas. Para ficar apenas no âmbito da pesquisa primatológica, pode-se enunciar alguns. As condições de observação, por exemplo, promovem uma intensificação das interações entre humanos e não humanos. Métodos que contemplam observação prolongada, convívio próximo e, às vezes, interativo, assim como o enfoque no comportamento, reforçam potencialmente a identificação dos humanos com os animais e restringem o distanciamento do observador em relação ao observado.Nesse contexto, a antropomorfização ou a zoomorfização (cf. Asquith, 2011) são fatores a serem considerados. A humanização do comportamento é um aspecto da observação em primatologia que pode ser encarada como um risco (cf. Morris, 2010) ou como um aspecto positivo que deve ser cultivado na aplicação do método. Ou seja, humanizar o comportamento dos animais, atribuindo-lhes "medo", "confiança", "interesse", "curiosidade" ou qualquer atributo desse tipo, é uma conduta de pesquisa que aparece qualificada por um espectro de atitudes tão distintas que vão do controle e da rejeição (Altman apud Hrdy, 2000 , p. 64) à incorporação como uma estratégia positiva para acessar o fenômeno, desde que controlada (cf. Mithchel \& Hamm, 1997, p. 174-5). 
A antropóloga Pamela Asquith (2011) tratou dessa questão explorando como os vínculos entre humanos e não humanos levam os primatólogos a modificar as fronteiras de classificação entre ambos. A proposta da expressão "culturas de chimpanzés" seria, segundo ela, um exemplo direto disso. O convívio entre primatólogos e primatas também leva ao envolvimento do pesquisador com questões locais complexas relacionadas à sobrevivência de humanos e não humanos (guerras civis, fome, epidemias, práticas culturais) nas florestas africanas (cf. Goodall, 1991; Jahme, 2001) e problemas éticos, de manutenção de projetos e conflitos de interesse em laboratórios (cf. Fouts, 1998; De Waal, 2004). Em suma, por várias razões, algumas louváveis, outras não, a aproximação entre humanos, primatólogos ou não, e primatas não humanos em nossa sociedade parece inexorável e irreversível. Ora, esse tema é mesmo um filão para a discussão antropológica, dado que a antropologia vem perguntando, desde os seus primórdios, sobre os mecanismos subjacentes à "estranha conduta" de populações tribais, segundo a qual animais, plantas, fenômenos naturais e outros fatores poderiam ser classificados em conjuntos com os seres humanos, gerando uma tal configuração cultural que permite, por exemplo, que humanos vejam-se, sintam-se e comportemse como descendentes, por exemplo, de um jabuti, de uma onça ou de uma serpente ou, ainda, vejam babuínos e chimpanzés como uma tipo de parente, ao mesmo tempo em que sabem claramente que são humanos e não animais. Esse fenômeno, denominado originalmente como totemismo, ou animismo em alguns casos, era atribuído à suposta incapacidade de discernimento de populações tribais, mas foi posteriormente deslocado de sua especificidade por Lévi-Strauss (cf. 1986[1958]), que percebeu que tal mecanismo - o da elaboração de um tipo de pensamento que "humaniza" a natureza e "naturaliza" os humanos, de modo a permitir-lhes partilhar características comuns - é próprio do modo humano de pensar a natureza, apesar de manifestar-se, segundo seus próprios termos, em cada cultura humana. Projetando isso sobre a pesquisa primatológica e sobre as redefinições futuras e possíveis de humano e de animal, pode-se considerar que, talvez, as dificuldades enfrentadas estejam diretamente relacionadas aos alicerces do modo humano de pensar que, por ser universalmente simbólico, atribui significados e indica os fundamentos comuns que se manifestam tanto no pensamento mítico quanto no pensamento científico (cf. Kuper, 1999). 


\title{
Eliane Sebeika Rapghan
}

Departamento de Ciências Sociais, Universidade Estadual de Maringá, Paraná. Laboratório de Estudos Evolutivos Humanos, Universidade de São Paulo, Brasil. elianesebeika65@gmail.com

\section{Walter Alves Neves}

Instituto de Biologia,

Laboratório de Estudos Evolutivos Humanos,

Universidade de São Paulo, Brasil.

waneves@usp.ib.br

\section{Primatology, non-human cultures, and new kinds of otherness}

\begin{abstract}
The relations between humans and non-human primates resemble the ethnocentric reaction of one human culture in relation to others, and include an estrangement marked by attraction and rejection, identification and differentiation. Art, science and myths are the vivid and updated expression of these phenomena. Since the 1960's primatology stands out in that scenario for contributing significantly to the revision of the definitions about the behavior of primates and, consequently, for the redefinition of human beings, and for making the controversial proposal of the existence of non-human animal "cultures". Then, the close connection between humans and non-human primates seems relentless and irreversible - and raises the question on whether or not these processes engender a new kind of otherness deriving from a non-human other that is full of meaning. This would include, for example, the reformulation of the representations and categories of classification, as well as deepening the debate about the rights of non-human animals. When the challenge is taken up in situations of anthropological research that address the relationships between human beings and the other primates, the ethnographic register that describes the relations between human beings and other primates will be an equally sharp empirical, perceptual and theoretical construction. Given the peculiar type of relationship established between human beings and other primates, implemented in a frontier universe of uncomfortable similarities and differences, they constituted a hybrid collective where interactions are possible but we do not know exactly how complex or how depth they are.
\end{abstract}

KeYwords • Otherness. Animality. Hybrid collective. Chimpanzee cultures. Ethnography. Hybrids. Humanity. Relations between humans and non-humans. 


\section{REFERÊNGIAS BIBLIOGRÁFIGAS}

Akhil, G. \& Ferguson, J. (Ed.). Culture, power, place. Explanations in critical anthropology. London: Duke University Press Books, 1997 .

Alvard, M. The adaptative nature of culture. Evolutionary Anthropology, 12, p. 136-49, 2003.

ArCADI, A. C. Vocal responsiveness in male wild chimpanzees: implications for the evolution of language. Journal of Human Evolution, 39, p. 205-33, 2000.

Language evolution: what do chimpanzees have to say? Current Biology, 15, 21, p. R884-6, 2005.

Arcadi, A. C. \& Wrangham, R. W. Infanticide in chimpanzees: review of cases and a new within-group observation from de Kanyawara study group in Kibale National Park. Primates, 4, , 2, p. 337-51, 1999.

Armstrong, S. \& Bitzler, R. G. (Ed.). The animal ethics reader. London: Routledge, 2003.

Arnold, K. \& Withen, A. Post-conflit behaviour of wild chimpanzees (Pan troglodytes schweinfurthii) in the Bundongo Forest, Uganda. Behaviour, 138, p. 649-90, 2001.

Arnold, K. \& ZuberbüHLer, K. Meaningful call combinations in a non-human primate. Current Biology, 18,15 , p. R2O2-3, 2008.

Arsuaga, J. L. O colar do neanderthal. Em busca dos primeiros pensadores. Rio de Janeiro: Globo, 2007.

Asquith, P. J. Of monkeys and men: cultural views in Japan and the West. In: Corbey, R. \& Theunissen, B. (Ed.). Ape, man, apeman: changing views since 1600. Leiden: Leiden University, 1995 p. 309-18.

. Of bonds and boundaries: what is the modern role of anthropomorphism in primatological studies? American Journal of Primatology, 73 , p. 238-44, 2011.

Barkow, J. et al. (Ed). The adapted mind. Oxford: Oxford University Presses, 1992.

Betzig, L. (Ed.). Human nature: a critical reader. Oxford: Oxford University Press, 1997.

Introduction: people are animals. In: Betzig, L. (Ed.). Human nature: a critical reader. Oxford: Oxford

University Press, 1997·p. 1-17.

Bozsch, C. Symbolic communication in wild chimpanzees? Human Evolution, 6, 1, p. 81-90, 1991.

Is culture a golden barrier between human and chimpanzee? Evolutionary Anthropology, 12, p. 8291, 2003.

. From material to symbolic cultures: culture in primates. In: VAlsiner, J. (Org.). The Oxford handbook of culture and psychology. Oxford: Oxford University Press, 2011. p. 677-93.

Bozsch, C. \& Bozsch, H. Tool use and tool making in wild chimpanzees. Folia Primatologica, 54, p. 86-99, 1990.

BurLing, R. Primate calls, human language and nonverbal communication. Current Anthropology, 34, 1, p. $25^{-} 5^{3,1993 .}$

. The talking ape: how language evolved. New York: Oxford University Press, 2007.

Garpenter, M.; Tomasello, M. \& Savage-Rumbaugh, S. Join attention and imitative learning in children, chimpanzees, and acculturated chimpanzees. Social Development, 4, 3, p. 217-38, 1995.

Cavalieri, P. \& Singer, P. The great ape project. In: Corbey, R. \& Theunissen, B. (Ed.). Ape, man, apeman: changing views since 1600. Leiden: Leiden University, 1995. p. 367-76.

ClaAstres, P. A sociedade contra o estado. São Paulo: Cosac Naify, 2012.

Corbey, R. \& Theunissen, B. (Ed.).Ape, man, apeman: changing views since 1600. Leiden: Leiden University, 1995 .

Cronk, L.; Chagnon, N. \& Irons, W. (Ed.). Adaptation and human behavior: an anthropological theory. New York: Aldine and Gruyer, 2000.

Davidson, I. \& MgGrew, W.C. Stone tools and the uniqueness of human culture. The Journal of the Royal Anthopology Institute, 11, 4, p. 793-817, 2005 . 
De WAAL, F. B. M. Cultural primatology comes of age. Nature, 399, 17, p. 635-6, 1999.

Chimpanzee politics: power and sex among apes. Baltimore: The Johns Hopkins University Press, 2000. Evolutionary ethics, aggression, and violence: lessons from primate research. Journal of Law, Medicine \& Ethics, 32, p. 18-23, 2004.

Our inner ape: a leading primatologist explains why we are who we are. New York: Riverhead Books, 2005 a.

A century of getting to know the chimpanzee. Nature, 437, p. 56-9, 2005b.

Deleuze, G. \& Guattari, G. Mille plateaux. Paris: De Minuit, 1980.

Devore, I. (Ed.). Primate behavior. Field studies of monkeys and apes. New York: Holt, Rinehantand Winston, 1965 .

Diamond, J. The rise and the fall of the third chimpanzee: evolution and human life. London: Vintage Digital, 2013.

Drennan, R. Pré-Hispanic chiefdom trajectories in Mesoamerica, Central America and Northern South America. In: Earle, T. (Ed.). Chiefdoms, power, economy, and ideology. Cambridge: Cambridge University Press, 1991. p. 263-87.

Dunbar, R. The social brain hypothesis. Evolutionary Anthropology, 7, 1, 178-90, 2002.

Dunbar, R. \& Schultz, S. The evolution of the social brain: anthropoid primates contrast with other vertebrates. Proceedings of the Royal Society. Biological Sciences, 274, 1624, p. 24,29-36, 2007.

Earle, T. (Ed.). Chiefdoms, power, economy, and ideology. Cambridge: Cambridge University Press, 1991

ElLen, R.; Lycett, S. J. \& Johns, S. E. Cultural transmission in anthropology: a critical synthesis. New York: Berghan Books, 2013.

Fedigan, L. Primate paradigms. Chicago: University of Chicago Press, 1992.

Foley, R. Another unique species: patterns in human evolutionary ecology. London: Longman, Sc \& Tec, 1987 .

Fouts, R. O parente mais próximo. Rio de Janeiro: Objetiva, 1998.

Galdikas, B. \& Vasey, P. Primatology. In: Maxwell, M. (Ed.). The sociobiological imagination. Albany: State of New York Press, 1991. p. 111.

GALEF, B. The question of animal culture. Human Nature, 3, p. 157-78, 1992.

Gangestad, S. W. \& Simpson, J. A. (Ed.). The evolution of mind: fundamental questions and controversies. New York: Guilford Publications, 2007.

Geertz, G. A interpretação das culturas. Rio de Janeiro: Zahar, 1978.

Gilmore, H. G. From Radcliffe-Brown to sociobiology: some aspects of the rise of primatology within physical anthropology. American Journal of Physical Anthropology, 56, 4, p. 387-92, 1981.

Goodall, J. Chimpanzees of Gombe stream reserve. In: Devore, I. (Ed.). Primate behavior. Field studies of monkeys and apes. New York: Holt, Rinehantand Winston, 1965. p. 425-73.

Uma janela para a vida: 30 anos com os chimpanzés da Tanzânia. Rio de Janeiro: Zahar, 1991.

Gould S. J. Ontogeny and phylogeny. Cambridge: Harvard University Press, 1977.

The structure of evolutionary theory. Harvard: Harvard University Press, 2002.

Hanke, L. All mankind is one: a study of the disputation between Bartolomé de Las Casas and Juan Ginés de Sepulveda on the religious and intellectual capacity of the American Indians. Nothern Illinois: University Press, 1994.

Haraway, D. Primate visions: gender, race, and nature in the world of modern science. New York: Routledge, 1989.

Simians, cyborgs, and women: the reinvention of nature. New York: Routledge, 1990.

Henrich, J. \& MaElreath, R. The evolution of cultural evolution, Evolutionary Anthropology, 12, p. 123$35,2003$.

Hrdy, S. B. Mother nature: maternal instincts and how they shape the human species. New York: Ballantine, 2000. 
Holzhaider, J. G.; Sibley, M. D.; Taylor, A. H.; Singh, P. J.; Gray, R. D. \& Hunt, G. R. The social system of New Caledonian crows. Animal Behaviour, 81, p. 83-92, 2011.

InGold, T. (Org.). Companion encyclopedia of anthropology. London: Routledge, 1994. Humanity and animality. In: IngoLd, T. (Org.). Companion encyclopedia of anthropology. London: Routledge, 1994. p. 14,-32.

(Ed.). Key debates in anthropology. London: Routledge, 1996.

The use and abuse of ethnography. Behavioral and Brain Sciences, 24, 2, p. 337, 2001.

Irons, W. \& Cronk, L. Two decades of a new paradigm. In: Cronk, L.; Chagnon, N. \& Irons, W. (Ed.) Adaptation and human behavior: an anthropological theory. New York: Aldine and Gruyer, 2000. p. 326.

Jahme, C. Beauty and the beasts: women, ape, and evolution. New York: Soho Press, 2001.

Janson, C. H. \& Sмiтн, E. A. The evolution of culture: new perspectives and evidences. Evolutionary Anthropology, 12, 2, p. 57-60, 2003.

Kappeler, P. M. \& Silk, J. B. (Org.). Mind the gap: tracing the origins of human universals. New York: Springer, 2010.

King, B. J. The dynamic dance. Nonvocal communication in African great apes. Cambridge: Harvard University Press, 2004.

Kuein, R. G. The human career: human biological and cultural origins. Chicago: University of Chicago Press, 2009 [1999].

Kojima, S.; Izumi, A. \& Ceugniet, M. Identification of vocalizers by pant hoots, pant grunts and screams in a chimpanzee. Primates, 44, p. 225-30, 2003.

Kroeber, A. L. \& Klucknonn, C. Culture. A critical review of concepts and definitions. Cambridge: Cambridge University Press, 1952.

Kuper, A. Culture: the anthropologist's account. Cambridge: Harvard University Press, 1999.

Lachmann, M.; Számadó, S. \& Bergstrom, C. T. Cost and conflict in animal signals and human language. PNAS, 98, 23, p. 13189-94, 2001.

LaLand, K. N. Animal cultures. Current Biology, 18, 9, p. R366-70, 2008.

Latand, K. N. \& Galef, B. G. (Ed.). The question of animal culture. Cambridge: Harvard University Press, 2009.

Latour, B. Jamais fomos modernos. Ensaio de antropologia simétrica. Rio de Janeiro: Editora 34, 1994. A well-articulated primatology. Reflexions of a fellow-traveler. In: Strum, S. \& Fedigan, L. (Ed.). Primate encounters. Chicago: University of Chicago Press, 2000. p. 358-81.

Lestel, D. L'innovation cognitive dans des communautés hybrides homme/animal de partage de sens, d'intérêts et d'affects. Intellectia, 1-2 (26-27), p. 203-26, 1998. . As origens animais da cultura. Lisboa: Instituto Piaget, 2002. L'animal singulier. Paris: Seuil, 2004.

Lévi-Strauss, C.A eficácia simbólica. Antropologia estrutural. Rio de Janeiro: Tempo Brasileiro, 1986 [1958].

Lycett, S. J.; Collard, M. \& MaGrew, W. C. Are behavioral differences among wild chimpanzee communities genetic or cultural? An assessment using tool-use data and phylogenetic methods. American Journal of Physical Anthropology, 14,2, p. 4,61-7, 2010.

Mason, W. A. \& Mendoza, S. P. (Ed.). Primate social conflict. Albany: State University of NewYork Press, 1993.

Matsuzawa, M. (Ed.). Primate origins of human cognition and behaviour. Tokio: Springer-Verlag, 2001. Primate foundations of human intelligence: a view of tool use in nonhuman primates and fossil hominids. In: MatsuZawa, M. (Ed.). Primate origins of human cognition and behaviour. Tokio: SpringerVerlag, 2001. p. 3-25.

Mauss, M. Sociologia e antropologia. São Paulo: Cosac Naify, 2003. 
MaXwell, M. (Ed.). The sociobiological imagination. Albany: State of New York Press, 1991.

McGrew, W. C. Chimpanzee material culture: implications for human evolution. Cambridge: Cambridge University Press, 1992.

. Overiew. Diversity in social relations. In: Wrangham, R. W. et al. (Ed.). Chimpanzee cultures. Cambridge: Havard Univeristy Press/The Chicago Academy of Sciences, 2001. p. 21-3.

The cultured chimpanzee: reflections on cultural primatology. Cambridge: Cambridge University Press, 2004 .

McGrew, W. G. \& Tutin, C. E. G. Evidence for a social custom in wild chimpanzees? Man, 13, p. 243-51, 1978.

Miтнсhell, R. W. \& Hamm, M. The interpretation of animal psychology: anthropomorphism or behavior reading. Behavior, 134 , p. $173-204,1997$.

Mithen, S. A pré-história da mente. São Paulo: Editorial Unesp, 2002.

. General intellectual ability. In: Gangestad, S. W. \& Simpson, J. A. (Ed.). The evolution of mind: fundamental questions and controversies. New York: Guilford Publications, 2007. p. 6o-6.

Moran, E. F. (Ed.). The ecosystem approach in anthropology: from concept to practice. Ann Arbor: The University of Michigan Press, 1991.

Morris, D. The naked ape. A zoologist's study of the human animal. London: Vintage Digital, 2010.

Nishida, T. Local traditions and cultural transmission. In: Smuts, B. B. et al. (Ed.). Primate societies. Chicago: University of Chicago Press, 1987. p. 462-74.

Parker, S. T. \& Gibson, K. R. 'Language' and intelligence in monkeys and apes. Cambridge: Cambridge University Press, 1994 .

PERRY, S. What cultural primatology can tell anthropologists about the evolution of culture. Annual Review of Anthropology, 35, p. 171-90, 2006.

Pika, S. \& Mitani, J. Referential gestural communication in wild chimpanzees. Current Biology, 16, 6, p. Rig1-2, 2006.

PInKer, S. Language, cognition, and human nature: selected articles. Cambridge: Oxford University Press, 2013.

Poirier, F. E. \& Fitton, L. J. Primate cultural worlds: monkeys, apes and humans. Behavioral and Brain Sciences, 24, 2, p. 349-50, 2001.

RAPGHAN, E. S. On the state of nature and social life: thinking about humans and chimpanzees. Revue de Primatologie, 4, p. 2-17, 2012.

Rapchan, E. S. \& Neves, W. A. Chimpanzés não amam! Em defesa do significado. Revista de Antropologia, 48,2, p. 649-98, 2005.

. \& __. Etnografias sobre humanos e não humanos: limites e possibilidades. Revista de Antropologia, 57,1 . No prelo.

Rendell, L. \& Whitehead, H. Culture in whales and dolphins. Behavioral and Brain Sciences, 24, 2, p. $3 \circ 9-82,2001$.

Richerson, P. \& Boyd, R. Not by genes alone: how culture transformed human evolution. Chicago: University of Chicago Press, 2005.

SÁ, G. No mesmo galho: antropologia de coletivos humanos e animais. Rio de Janeiro: 7 Letras, 2013.

SANtos, B. S. Um discurso sobre as ciências na transição para uma ciência pós-moderna. Estudos Avançados, 2, 2, p. 46-71, 1988.

Sмiтн, E. A. Three styles in the evolutionary analysis of human behavior. In: CRonk, L.; Chagnon, N. \& Irons, W. (Ed.).Adaptation and human behavior: an anthropological theory. New York: Aldine/Gruyer, 2000. p. $27-4,6$.

Smuts, B. B. et al. (Ed.). Primate societies. Chicago: University of Chicago Press, 1987.

Sperber, D. On anthropological knowledge: three essays. London: Cambridge, 1985. 
Stanford, C. B. The social behavior of chimpanzees and bonobos: empirical evidence and shifting assumptions. Current Anthropology, 39, 4, p. 399-420, 1998.

The significant other. New York: Basic Books, 2001.

Strum, S. \& Fedigan, L. (Ed.). Primate encounters. Chicago: University of Chicago Press, 2000.

Tomasello, M. The question of chimpanzee culture. In: Wrangham, R. et al. (Ed.). Chimpanzee cultures. Cambridge: Harvard University Press, 2001. p. 201-318.

Tomasello, M. \& Call, J. (Ed.). Primate cognition. New York: Oxford University Press, 1997.

Tоoвy, J. \& Cosmides, L. The psychological foundations of culture. In: Barkow, J. et al. (Ed). The adapted mind. Oxford: Oxford University Press, 1992. p. 19-139.

Valsiner, J. (Org.). The Oxford handbook of culture and psychology. Oxford: Oxford University Press, 2011.

WAIZBoRt, R. Teoria social e biologia: perspectivas e problemas da introdução do conceito de história nas ciências biológicas. História, Ciências e Saúde-Manguinhos, 8, 3, p. 633-53, 2001.

Watts, D.; Potts, K. B.; Lwanga, J. S. \& Mitani, J. C. Diet of chimpanees (Pan troglodytes schweinfürthi) at Ngongo, Kibale National Park, Uganda. American Journal of Primatology, 74, 2, p. 114-29, 2012.

WeIss, K. \& Hayashida, F. Kultur crisis! Cultural evolution going round in circle. Evolutionary Anthropology, 11, p. 136-41, 2002.

Whiten, A. The second inheritance system of chimpanzees and humans. Nature, 437, p. 52-5, $2005 \mathrm{a}$. Animal culture is real but needs to be clearly defined. Nature, 438, p. $107^{8}, 2005^{\mathrm{b}}$.

. Ape behavior and the origins of human culture. In: Kappeler, P. M. \& Silk, J. B. (Org.) Mind the gap: Tracing the origins of human universals. New York: Springer, 2010. p. 429-50.

Whiten, A. \& Boesch, C. The cultures of chimpanzees. Scientific American, 284, p. 60-7, 2001.

Whiten, A. et al. Cultures in chimpanzees. Nature, 399, p. 682-5, 1999.

Whiten, A.; Schick, K. \& Toтн, N. The evolution and cultural transmission of percussive technology: integrating evidence from paleoanthropology and primatology. Journal of Human Evolution, 57, 4, p. $420-35,2009$.

Witerhalder, B. \& Smith, E. A. Evolutionary ecology and the social sciences. In: Witerhalder, B. \& Smith, E. A. (Org.). Evolutionary ecology and human behavior. New York: Aldine de Guyter, 1992. p. 3-23.

Witerhalder, B. \& Smith, E. A. (Org.). Evolutionary ecology and human behavior. New York: Aldine de Guyter, 1992.

Wrangham, R. W. et al. (Ed.). Chimpanzee cultures. Chicago: Harvard University, 2001.

Zeller, A. Chimpanzee grooming as social custom. American Anthropologist, 103, 1, p. 193-6, 2001. 